\title{
Does Organizational Culture Effect on Association Between Intellectual Capital and Cost Characteristics?
}

Mehdi Heidari*, Hamze Didar and Yaser Vafa

Department of Accounting, Faculty of Economics and Administrations, Urmia University, Urmia, Iran

\begin{abstract}
Purpose: In line with the knowledge-based economy development, their intellectual capitals play a vital role in achieving a sustainable competitive advantage. In the context of developing economy, cost management is taken into consideration as one of the most important strategies to attain financial success and organizational performance within the competitive market. Since intellectual capital and cost characteristics management are among the factors leading to improvement of financial performance indicators among companies, and considering the fact that these terms can function as improving the efficiency and effectiveness in assumed organizations along with perceiving that organizational culture is one of the fundamental fields of organizational change and transform, the present study was developed to examine the association between intellectual capital and cost characteristics with a focus on mediating effect of organizational culture among the companies listed in Tehran Stock Exchanges and over the counter.
\end{abstract}

Design/methodology/approach: To this end, the information pertinent to 168 companies for 7 years through 2010 to 2016 was used. To test the research hypotheses, the present study made use of multivariate regression method based on mixed data

Findings: The results indicated that there was a positive and significant relationship between intellectual capital and organizational culture as well as cost characteristics. In addition, it was concluded that there was a positive and significant relationship between organizational culture and cost characteristics. Ultimately, it was found that the effect of organizational culture (as the mediator variable) in the relationship between intellectual capital and cost characteristics was significant.

Originality/value: Organizational culture models play a key role in increased managers' awareness and organizational practitioners. It is necessary that organizational managers, particularly in developing countries pave the way for increased efficiency and organizational effectiveness through referring of mixed models and develop strategic studies with respect to the conformation of these models.

Keywords: Intellectual capital; Cost characteristics; Organizational culture

\section{Introduction}

Despite the fact that there are a variety of definitions regarding the term intellectual capital, there is also a consensus over the economicoriented and knowledge-oriented approaches so that a considerable number of researchers have identified human capital, structural capital and client capital as the potential comments of the intellectual capital. The intellectual capital offers a number of advantages such as profitmaking, improving the strategic position, increasing the market share, innovation and exclusive technology, developing the standard and recognizing the trademark, increasing organizational fame, reducing the expenses, increasing client loyalty and improving the productivity. One of the benefits of intellectual capital for the organization is the reduction of costs. The cost reduction is performed through the management of costs. Cost management involves the efficiency and optimal use of the organization resources in order to create the values, norms and social behaviors which have an impact on the behavior and attitudes of individuals within the organization. Generally speaking, culture is said to be supportive of knowledge management when it creates value for the knowledge and encourages it sharing, creation, and application. Thus, developing a comprehensive definition of organizational culture and knowledge management is a key step towards the development of intellectual capitals. Edwinson considers the cultural and organizational values as the outcomes of firm's human capitals. The researchers believe that culture shapes various cultures and makes them related to one another. Affecting all dimensions of organization, organizational culture is of such significance that the management scientists take into consideration the main task of leaders as change and assigning proper cultural values. In general, the organization culture has impacts on organizational improvement more than the environmental factors. Hajiha and Kharatzade [1] in a study were carried out to compare the organizational culture and its dimensions among the companies which make use of the management accounting innovations and those who avoid using them. There was found to be a significant difference between the organizational culture of the companies which make use of the management accounting innovations and companies which refrain from using them. Therefore, one can state that organizational culture has an effect on the use of management accounting innovations such as the cost management, and one can draw the attention towards examining the association between the organizational culture and cost characteristics. In addition, considering the effect of intellectual capital and cost management on the financial performance of firms, one can investigate the effect of intellectual capital in cost characteristics. Also, since the culture is

${ }^{*}$ Corresponding author: Mehdi Heidari, Assistant Professor, Department of Accounting, Faculty of Economics and Administrations, Urmia University, Urmia, Iran, Tel: +44-32777022; E-mail: m.heydari@urmia.ac.ir

Received April 28, 2018; Accepted May 22, 2018; Published June 24, 2018

Citation: Heidari M, Didar H, Vafa Y (2018) Does Organizational Culture Effect on Association Between Intellectual Capital and Cost Characteristics?. J Account Mark 7: 277. doi: 10.4172/2168-9601.1000277

Copyright: $\odot 2018$ Heidari M, et al. This is an open-access article distributed under the terms of the Creative Commons Attribution License, which permits unrestricted use, distribution, and reproduction in any medium, provided the original author and source are credited. 
considered as the strategic touchstone for a successful company, one can explore the influence of intellectual capital on organizational culture, accordingly. Thus, the purpose of the present study is to examine the effect of intellectual capital on cost characteristics with respect to the role of organizational culture as the mediator variable.

\section{Review Literature and Previous Researches}

\section{Intellectual capital}

Today, management of intellectual capital would lead the organizations towards higher levels of success across competitive markets. The first attempts dealing with the concepts of intellectual capital were achieved by the studies of Fritz Machlupin [2]; however, the invention of the intellectual capital term is attributed to Galbrais. In recent decades, companies (firms) have devoted their attention towards measuring the intellectual capital for offering reports for the beneficiary parties where they attempt to find out methods for assessing the local intangible assets and extracting the intangible values across organizations [3]. The intellectual capital offers a new comprehensive model for observing the real values of organizations through the use of which one can evaluate the future values of the company. Most of the experts consider the intellectual capital as involving client capital, human capital and structural capital. The intellectual capital can be defined as the set of all knowledge which is employed by the employees of companies, which also creates competitive advantage. Putting into other words, the intellectual capital is defined as the intellect axis including the knowledge, information, assets and intellectual analysis through the use of which companies can benefit from the advantage towards the generation of wealth [3].

\section{Cost management}

Rapid and astonishing development of technology along with the increased competition in global markets have encouraged the economic managers to produce high-quality products, offering optimal services to clients and reducing the final cost of products and services. Companies which have adopted the cost management strategy will be able to increase their market share through suggesting lower costs for production and sale. In general, cost management system emphasizes minimizing the production costs and excluding any activity without added economic value as well as progressing towards high-quality products [4]. Cost management is based on the attitude that costs are not generated by themselves; rather, it is the all reducing costs or embarking on product services as well as management decisions that are based on the use of limited organizational resources. The attitude of cost management plays a vital role in shaping the managers' decisions towards creating value for all beneficiary parties (stakeholders, clients, employees, and society) and endeavors to offer a balanced and creative level among different beneficiary parties.

\section{Organizational culture}

Organizational culture is a term which has been newly developed in the field of management knowledge and organismal behaviors. Following the new theories and studies in the context of management, the organizational culture has captured the attention and is regarded as one of the concerns within the field of management [5]. In fact, the organizational culture has been realized in the belief system of organization and is defined frequently by the language, symbols, traditional and customer which reflect the behavior derived from the belief system. Defections of organizational culture have to do with explaining the quality of behavior or people's thinking styles. In an attempt to achieve a useful and comprehensive definition, some of the researchers such as Gerioz, Walter and Dabsen have considered the cultural performances while some others such as Bawer and Gonzalez have developed a brief definition in this regard. Thus, considering the importance of definitions offered concerning the term organizational culture, a number of definitions are demonstrated in this section. Shain [6] related the organizational culture to an iceberg, the overall image of which is latent and a tiny part of it is observable. From Hafsted's [7] point of view, organizational culture is a collective planning in within the mind. Mind planning is not the same as that of the computer. Considering the effect of intellectual capital and cost management on the financial performance of companies, one can examine the impact of intellectual capital on cost characteristics. Since culture is regarded as a strategic touchstone for a successful company, one can address the effect of intellectual capital on organizational culture. Based on the results obtained from the research hypotheses, one can say there is a significant difference between the organizational culture of companies which make use of this innovation and those which refrain from using it. Generally speaking, one can argue that organizational culture has an effect on the application of management accounting innovation such as the cost management and one can examine the association between organizational culture and cost characteristics.

\section{Previous researches}

Alameh and Mousavidi [8] have examined the intellectual capital effect on cultural capital, knowledge management actions and organizational performance among the employees working in Isfahan Gas Company. In this study, the human and structural capitals were found to have an effect on the organizational performance. In addition, this component had an effect on the organizational performance indirectly with the mediator variable role of cultural capital and $\mathrm{KM}$ actions.

Zahela et al. [9] have examined the linkages between management accounting systems (MAS), enterprise risk management (ERM) and organizational performance by examining MAS information characteristics that match ERM implementation and joint effects of MAS and ERM on organizational performance. Fakhari and Mohamadi [10] in a study was developed to addresses the effect of organizational culture on the quality of information disclosure. The results indicated that some of the organizational culture components (adaptation and missionary) had an effect on the disclosure of information among companies. However, no significant relationship was found between the organization culture based on the job involvement and adaptation to the disclosure quality as well as its expression. Such results can be useful for implementing the method of response responsibility, leading to increased information disclosure clarity within the companies. ElKelish and Hassan [11] showed in their study regarding the organizational culture ad disclosure of risk among large companies that hierarchical organizational culture had a positive and significant effect on the level of risk disclosure of United Arabic Emirates company's rich level. The researchers examine the organizational culture based on the cultural dimensions model of Mozhen and its association with employing management accounting innovations among the companies listed in Tehran Stock Exchanges. Considering management accounting innovations of this research included: Activity-based costing, activitybased management, balanced evaluation, goal-based costing, standard costing, quality costing and Kaizen costing. The organizational culture dimensions were found to be supporting tendencies, innovation, rulebased tendencies and goal-based tendencies. Based on the findings, there was a significant difference between the companies which make use of the management accounting innovations and those which refrain 
from using them. Fakhari and Mohamadi [10] concluded in their study that removing of added value, enhancement of fixed expenses in line with the incomes, reduction of non-fixed costs and improvement of main activities within the economic sectors are in correlation with the financial performance of institute. The results of the study Sanchez et al. [12] manifested that organizational culture is considered as the main component within demonstrated models with respect to the evaluation of intellectual capital, and there is a strong relationship between culture and components of intellectual capital [13]

\section{Research hypotheses}

Hypothesis one: Intellectual capital has significant effect on organizational culture

Hypothesis two: Organizational culture has significant effect on cost characteristics.

Hypothesis three: Intellectual capital has significant effect on cost characteristics.

Hypothesis four: Intellectual capital has significant effect on cost characteristics with considering the organizational culture.

\section{Methodology}

The required data were used based on the survey design and obtained from the information center of stock exchanges as well as financial reports of the companies listed in stock exchanges and over the counter companies' center. Also, the data were gathered from the Board of Directors of companies listed in Tehran Stock Exchanges and over the counter companies. Later, the data were analyzed after being ordered by the considered software and the statistical analysis. The sampling method is based the systematic removing method. therefore, the chosen model included the companies listed in Stock Exchanges and over the counter companies which met the following characteristics: the company is admitted to Tehran Stock Exchanges since 2010; the financial year ends in December 31 and that the company has not changed its financial year between the years 2010 to 2016; the required information for estimating the research variables are available for the considered years; it is not ranked as the banks and financial institutes (investment companies, financial mediation, banks, and leasing) since their financial disclosure differs. Considering the afore-mentioned conditions and based on the systematic removing method, the model was determined as 168 companies for the years 2010 to 2016 .

\section{Research variables}

Independent variable: Intellectual capital (IC): A model developed by Ante Palik dealing with the coefficient of the added value of intellectual capital which is an analytic instrument for measuring the performance of the company. Instead of direct measurement of intellectual capital, the author suggested a criterion for the efficiency of added value by the intellectual capability. The main components of the intellectual capital added value can be identified based on the company resources in the field of physical capital, human capital and structural capital. This model emphasizes the creation of company value based on the effectiveness of company resource management. Following is the equation for estimating the added value coefficient of the intellectual capital:

\section{$\mathrm{VAIC}=\mathrm{HCE}+\mathrm{SCE}+\mathrm{CEE}$}

Where, HCE: Human Resources Efficiency; SCE: Structural Capital Efficiency; CEE: Physical Capital Efficiency.

Dependent variable: Cost characteristics: there are different aspects of examining the cost characteristics and previous studies did not take into consideration such aspects. Thus, the following operational definition was developed through examining the cost characteristics of the management concept: the modulus of the ratio dealing with percent of changes in overhead costs to the production costs (overhead cost/production cost); the modules dealing with the percent of changes in production cost to the cost of sale goods (production cost/cost of sale goods); and the modulus of the percent of changes in quality costs of the production cost (quality cost/production cost) where the product costs, as well as the quality costs, are obtained from the financial statements and descriptive notations of the financial statements. The quality cost includes the rework cost, waste costs, machinery deficiency costs, after sale costs, guarantee costs, return from sale costs, off costs, and investigation as well as test costs, each of which is obtained from the financial statements and descriptive notations. The mean of each obtained changes percent is estimated for each company.

Mediator variable: Organizational culture (OC): to examine the organizational culture, Parson's AGIL model was used which included the initial actions in the field of developing a framework for understanding the values within the cultural systems, involving the organizational culture systems. Parson's model helps to assign the takes for each social system in order to survive. These tasks are as follows; adaptation: The ability to be adapted to the environment; goal development: having processes and reaching goals; integrity: integrating the components of organizational and their correlations; legitimacy: guarantying long life right by the surrounding components. Since different questionnaires have been previously used to examine the organizational culture, the present study made use of the information observation dealing with the report of directors' board. In case the assumed components are present in the reports of companies' board of directors, we enter the number 1; otherwise, we enter number zero where the total numbers indicate the organizational culture. Components of organizational culture and their quality of collection are shown in Table 1.

The control variables are as follows: financial leverage (FL): the financial leverage is defined as the ratio of sum of debts to the total asset; company size (size): company size is calculated through the logarithm of company's market value; loss rate: in case the company experiences the pure loss in one year, we enter number 1; otherwise, we enter number zero.

\section{Statistics Results}

\section{Descriptive statistics}

Descriptive statistics of the research variables are presented in the Table 2 .

\begin{tabular}{|l|l|}
\hline Components of organizational culture & Collection method \\
\hline Adaptation & Competitive status, the position of company in industry \\
\hline Goal development & Setting the plans and perspectives of company position in industry, level of achievement to determined goals \\
\hline Integrity & Level of investment in organizational integrated system such as IMS system \\
\hline Legitimacy & Organizational contracts \\
\hline
\end{tabular}

Table 1: Components of organizational culture and their quality of collection. 


\begin{tabular}{|c|c|c|c|c|c|c|}
\hline & Intellectual capital & Organizational culture & Cost characteristics & Financial leverage & Loss status & Company size \\
\hline Mean & 0.8439 & 0.7608 & 0.4597 & 0.5997 & 0.0824 & 6.1383 \\
\hline Median & 0.82 & 0.667 & 0.419 & 0.6075 & 0 & 5.9985 \\
\hline Maximum & 2.615 & 1 & 9.311 & 1.58 & 1 & 8.298 \\
\hline Minimum & 0 & 0.333 & 0.042 & 0.038 & 0 & 4.564 \\
\hline Standard deviation & 0.2887 & 0.1667 & 0.3535 & 0.2167 & 0.2752 & 0.7126 \\
\hline Coefficient of changes & 0.7690 & 0.2191 & 0.7690 & 0.3614 & 3.3366 & 0.1165 \\
\hline Jarque- Bera value & 537.16669 & 33.4120 & 703.2080 & 7.3245 & 4355.639 & 82.8878 \\
\hline Statistic value of Jarque-Bera & 0.0001 & 0.0001 & 0.0001 & 0.0256 & 0.0001 & 0.0001 \\
\hline Number of observations & 1176 & 1176 & 1176 & 1176 & 1176 & 1176 \\
\hline
\end{tabular}

Table 2: Descriptive statistics.

Based on the obtained values, one can say that the size of the commercial sector is the lowest change coefficient, thus it has the most stable condition throughout the seven-year period. The loss variable has the highest change coefficient; thus it has the minimum stable throughout the seven-year period compared to other research variables. One of the most important applications of descriptive statistics is to determine the normal or non-normal status of the variable. JarqueBera test is a suitable test in this regard. The statistic probability shows that the normality of variables distribution is rejected since their stasis is less than 0.05. Therefore, it is necessary to use Spearman correlation coefficient test to describe the variables. To identify the mixed data or panel data, Breusch-Pagan test is used, the results of which show that the panel model is confirmed. Since the type of model in panel data case should be determined between the fixed and random effects, Hausman test I used, the results of which indicate the choice of fixed effects model. Based on the results of Breusch-Pagan test, every three variables are examined through the use of panel data method. Also, based on the Hausman test results, every three hypotheses are tested based on the fixed effects method.

\section{Research hypotheses results}

Hypothesis 1: Intellectual capital has an effect on organizational culture.

The results of $\mathrm{F}$ statistical probability show that the model is significant in general; the self-correlation issue is resolved based on Durbin Watson statistic (Table 3). In addition, the results of the balanced determining coefficient show that $0.68 \%$ of the changes dealing with the dependent variable are determined by the independent and control variables of this test. The results indicate that the intellectual capital (with 0.2016 regression coefficient and 0.0001 probability) has a positive and significant effect on organizational culture. This means in case the intellectual capital changes, then the organizational culture will change by 0.2016 units. Also, the effect of control variable dealing with company size is positive and significant by 0.0001 probability. Control variables of financial leverage and loss status have a positive and significant effect on organizational culture with coefficients of 0.0168 and 0.0062 , respectively.

Hypothesis 2: Intellectual capital has an effect on cost characteristics.

The results of $\mathrm{F}$ statistical probability show that the model is significant in general, the self-correlation issue is resolved based on Durbin Watson statistic (2.1228) (Table 4). In addition, the results of the balanced determining coefficient show that $0.96 \%$ of the changes dealing with the dependent variable are determined by the independent and control variables of this test. The results indicate that the organizational culture (with 0.0479 regression coefficient and 0.0001 probability) has a positive and significant effect on cost characteristics. This means in case the organizational culture changes,

\begin{tabular}{|c|c|c|c|}
\hline \multicolumn{2}{|c|}{$\begin{array}{c}\text { Dependent 1 Table variable: } \\
\text { Organizational culture }\end{array}$} & \multicolumn{2}{c|}{ Fixed model of panel data type } \\
\hline T statistic probability & T statistic & Coefficients & Variables \\
\hline 0.0001 & 7.067 & 0.2016 & Intellectual capital \\
\hline 0.5515 & 0.5957 & 0.00168 & Financial leverage \\
\hline 0.6883 & 0.4013 & 0.0062 & Loss status \\
\hline 0.0001 & 12.4224 & 0.2216 & Company size \\
\hline 2.2426 & $\begin{array}{c}\text { Durbin Watson } \\
\text { statistic }\end{array}$ & 0.00629 & AR (1) \\
\hline 13.4153 & F statistic & 0.7342 & \begin{tabular}{c} 
Determining coefficient \\
\hline 0.0001
\end{tabular} \\
& F statistic probability & 0.6795 & $\begin{array}{c}\text { Balanced determining } \\
\text { coefficient }\end{array}$ \\
\hline
\end{tabular}

Table 3: Hypothesis-1 results.

\begin{tabular}{|c|c|c|c|}
\hline \multicolumn{2}{|c|}{$\begin{array}{c}\text { Dependent variable: Cost } \\
\text { characteristics }\end{array}$} & \multicolumn{2}{c|}{ Fixed model of panel data type } \\
\hline T statistic probability & T statistic & Coefficients & Variables \\
\hline 0.0001 & 7.6208 & 0.0479 & Organizational culture \\
\hline 0.9368 & 0.0770 & 0.0005 & Financial leverage \\
\hline 0.0863 & 1.7171 & 0.0063 & Loss status \\
\hline 0.0932 & -1.6806 & -0.0076 & Company size \\
\hline 2.1228 & $\begin{array}{c}\text { Durbin Watson } \\
\text { statistic }\end{array}$ & 0.0821 & AR (1) \\
\hline 139.6939 & F statistic & 0.9665 & Determining coefficient \\
\hline 0.0001 & F statistic probability & 0.9594 & $\begin{array}{c}\text { Balanced determining } \\
\text { coefficient }\end{array}$ \\
\hline
\end{tabular}

Table 4: Hypothesis-2 results.

then cost characteristics will change by 0.0479 units. Control variables of financial leverage and loss status have a positive but insignificant effect on cost characteristics with coefficients of 0.0005 and 0.0063 , respectively. Also, company size has a negative and insignificant effect (with -0.0076 coefficient) on cost characteristics.

Hypothesis 3: Intellectual capital has an effect on cost characteristics.

The results of $\mathrm{F}$ statistical probability show that the model is significant in general, the self-correlation issue is resolved based on Durbin Watson statistic (2.1398) (Table 5). In addition, the results of the balanced determining coefficient show that $0.96 \%$ of the changes dealing with the dependent variable are determined by the independent and control variables of this test.

Hypothesis 4: Intellectual capital has an effect on cost characteristics in companies listed in stock exchanges and over the counter companies with respect to the organizational culture.

To examine the mediating role of the organizational culture variable in the relationship between intellectual capital and cost characteristics, online Sobel test was used. In this test, the obtained Sobel test statistical probability is 0.018 and one can conclude that the hypothesis is accepted at $95 \%$ confidence interval. The results indicate that the intellectual 


\begin{tabular}{|c|c|c|c|}
\hline \multicolumn{2}{|c|}{$\begin{array}{c}\text { Dependent variable: Cost } \\
\text { characteristics }\end{array}$} & \multicolumn{2}{c|}{ Fixed model of panel data type } \\
\hline T statistic probability & T statistic & Coefficients & Variables \\
\hline 0.0033 & 2.9507 & 0.0208 & Intellectual capital \\
\hline 003834 & 0.8720 & 0.0054 & Financial leverage \\
\hline 0.0276 & 2.2067 & 0.0074 & Loss status \\
\hline 00.5621 & 0.5799 & 0.0025 & Company size \\
\hline 2.1398 & $\begin{array}{c}\text { Durbin Watson } \\
\text { statistic }\end{array}$ & 0.1125 & AR (1) \\
\hline 145.6895 & F statistic & 0.9677 & Determining coefficient \\
\hline 0.0001 & F statistic probability & 0.9611 & $\begin{array}{c}\text { Balanced determining } \\
\text { coefficient }\end{array}$ \\
\hline & & & \\
\hline
\end{tabular}

Table 5: Hypothesis-3 results.

capital (with 0.0208 regression coefficient and 0.0033 probability) has a positive and significant effect on cost characteristics. This implies that in case of intellectual capital changes, cost characteristics will change by 0.0208 units. Also, the effect of control variable dealing with loss status with 0.0276 probability is positive and significant. Financial leverage and company size with 0.0054 and 0.0025 coefficients have a positive but insignificant effect on cost characteristics.

\section{Conclusion and Suggestions}

The results show that intellectual capital has a positive and significant effect on organizational culture. This indicates that in case of intellectual capital change, organizational culture will change positively, accordingly. The results of this hypothesis are in line with the ones reported which aimed at examining the relationship between intellectual capital and organizational culture through the census of mediating managers working in Zanjan Chamber of Industry, Mine, and Commerce. The obtained results are also in line with that those of Felm Holtz' theories who considered the culture as basis for the organizational development and strategic touchstone for a successful company. The results of studies reported that organizational culture is considered in described models regarding the evaluation of intellectual capital as the main component, and there is a strong relationship between culture and components of intellectual capital. Organizational culture has a positive and significant effect on cost characteristics. This indicates that in case organizational culture changes then cost characteristics will change, accordingly. The results of this hypothesis are in accordance with previous studies results where it was found that there is a significant difference between the organizational culture of companies which make use of the management accounting innovations and those which refrain from using them. Hence, one can demonstrate that organizational culture has an effect on the use of management accounting innovations such as the cost management. Intellectual capital has a positive and significant effect on cost characteristics. This means in case intellectual capital has a positive and significant effect on cost characteristics. This means that in case intellectual capital changes, then the cost characteristics will change, adoringly. The result of this hypothesis proves the novelty of the present study since no local or international study has been conducted in this regard. Based on the studies undertaken in this domain, one can conclude that the increase of organizational culture among companies results in increased intellectual capital of companies and that cost management of companies would have positive effect on cost characteristics which results in profit-making, improvement of strategic position, increased market share, innovation and exclusive technology as well as recognition of commercial trademarks, increased organizational fame, redoing of costs, increased client loyalty and improvement of productivity. Based on the results obtained from the present study, following suggestions are presented or future studies. The set of organizational culture models play a key role in increased managers' awareness and organizational practitioners. It is necessary that organizational managers, particularly in developing countries pave the way for increased efficiency and organizational effectiveness through referring o mixed models and develop strategic studies with respect to the conformation of these models. Considering the role of intellectual capital in the success of companies and its contribution to the increased productivity and organizational fame as well as strategic position of companies, it is recommended that companies realize their information truly and give considerable attention towards the affective factors of stablishing intellectual capital. Also, it is suggested that the supervisory departments pave the way for more information disclosure of intellectual capital through assigning some guidelines, and embarking on encouraging polices. Base on the results of the hypothesis testing, higher levels of information disclosure in a company results in increased organizational culture level in an organization. Organizational culture would thus have an influence on cost characteristics so as to increase the profit-making, strategic position and reduce the costs. It is essential that companies draw more attention toward intellectual capital and its disclosure in their organizations, leading to profit-making, improvement of strategic positions, increased market share, innovation and exclusive technology as well as recognition of commercial trademarks, increased organizational fame, reduction of costs, increased client loyalty and improvement of productivity. Following this, the management section will make use of organizational resource expenses in an efficient and effective way in line with creating values for the clients where the profit-making and enterprise development are achieved through creating value. Clients are the basis for bringing wealth to the enterprises and organizations and it is the clients who show satisfaction and loyalty.

\section{References}

1. Hajiha Z, Kharratzadeh M (2015) The relationship between organizationa culture and use of management accounting innovations in companies listed in Tehran stock exchange.

2. Machlup F (1962) The production and distribution of knowledge in the United States. Princeton University Press.

3. Heydari M, Qaderi B, Kafami M (2016) The explanation relationship between corporate governance and intellectual capital from an agency theory perspective: A structural equation modeling approach 6: 131-151.

4. Khashei V, Khasti V (2017) The methods for measuring intellectual capital and economic added value. Quarterly on Accounting and Auditing 8: 98-121.

5. Tosi M (1972) Organizational culture. Tehran: Modiriat Dolati Publications.

6. Shain E (2003) Organizational culture. Didavar Publications.

7. Hofstede G (1986) Editorial: The usefulness of the 'organizational culture' concept. ¡ Manag Stud 23: 253

8. Allameh SA, Mousavidi ASA (2016) Investigating the influence of intellectual capital with the intermediate function of knowledge management and cultural capital on organizational performance from the perspective of the BSC Mode (Case study: Isfahan Gas Company). Management Accounting Quarterly 8: 73-87.

9. Zaleha ARS, Ruhana IC, Khairuzzaman WIW (2014) Management accounting systems, enterprise risk management and organizational performance in financial institutions. Asian Review of Accounting 22: 128-144.

10. Fakhari H, Mohamadi J (2017) The effect of organizational culture on information disclosure quality (timeliness and reliability). Accounting and Auditing Studies 23: 393-414.

11. ElKelish WW, Hassan MK (2014). Organizational culture and corporate risk disclosure: An empirical investigation for United Arab Emirates listed companies. International Journal of Commerce and Management 24: 279-299. 
Citation: Heidari M, Didar H, Vafa Y (2018) Does Organizational Culture Effect on Association Between Intellectual Capital and Cost Characteristics?. J Account Mark 7: 277. doi: 10.4172/2168-9601.1000277

Page 6 of 6

12. Sanchez CSM, Munoz MAA, Miguel AAM and Guzman TL (2007) Organizational culture and intellectual capital: A new model. Journal of Intellectual Capital 8 : $409-430$
13. Faghfori M, Porrashidi R, Salajge S (2014) Examining the association between organizational culture and intellectual capital: The case of mediating managers of Zanjan Chamber of Industry, Mine and Commerce. Second National Conference on New Management Sciences, Golestan, Gorgan. 